\title{
Gastrointestinal Helminthes Infesting Stray Dogs with Emphasis on Echinococcus Spp. in Nyala, South Darfur State, Sudan
}

\author{
El Malaik A. A. ${ }^{1}$; Elmahdi, I E ${ }^{2,4}$; Mohammed,AA ${ }^{1}$; Abakar, A D $^{3^{*}}$; \\ Ali Khalaf Ahmed Albaggar ${ }^{4}$ \\ ${ }^{1}$ Faculty of Veterinary Science, University of Nyala, Sudan. \\ ${ }^{2}$ Faculty of Health and Environmental Sciences, University of Gezira, Wad Medani, Sudan. \\ ${ }^{3}$ Department of Medical Parasitology, Faculty of Laboratory Medical Sciences, University of Gezira, \\ Wad Madani, Sudan. \\ ${ }^{4}$ Faculty of Applied Medical Sciences, Albaha University, KSA \\ Corresponding author: adamfafom@yahoo.com
}

\begin{abstract}
Dogs are important animals that serve in transmission of E. granulosus; they also play a major role as vectors for many zoonotic parasite, bacteriae and viruses in the Sudan. The current study reports on presence of gastrointestinal helminthes with emphasis on E granulosus. During a rabies control campaign, conducted in 2011 at Nyala South Darfur State, 117 stray dogs investigated. Postmortem examination revealed that, 95.7\% of examined animals were infected with one or more GIT parasite worms. The worms identified in dogs were: Ancylostoma caninum (62.4\%), Dipylidium caninum (1.7\%), Taenia spp. (89.7\%) and Echinococcus granulosus (6.8\%). No difference in the prevalence was observed between young and old dogs. Although male dogs had higher worm burdens than females, no difference in susceptibility was found between male and female dogs. Moreover, no differences in the prevalence was observed between the southern and northern areas of Nyala although the infected dogs of the northern areas had higher worm burdens than those in the South. Thus, open abattoirs and clandestine slaughterhouses appear to be the main reasons for the high prevalence of canine echinococcosis in the study area.
\end{abstract}

\section{INTRODUCTION}

Echinococcosis due to Echinococcus granulosus has become a major human and veterinary public health problem resulting in significant economic losses in sub-Saharan Africa as well as many other parts of the world. The life cycle of Echinococcus granulosus includes dogs and other canids as the definitive hosts of the adult parasite and numerous ungulates are intermediate hosts, harbouring the hydatid cyst (Moro and Schantz, 2006; Euzeby, 1991 and Garippa et al., 2004). However, the high prevalence of echinococcosis in dogs either in rural or in peri-urban areas and the high proportion of stray and free roaming dogs lead to a very high pollution of the environment by E. granulosus eggs (Dakkak, 2003). Moreover, Andersen (1997) stated that the nomadic rural inhabitants in the developing countries live under poor sanitary conditions without adequate supplies of clean water, large stray dog population, uncontrolled slaughter of meat animals, poor meat hygiene practices and live in close proximity to their domestic animals. Accordingly, many workers have reported echinococcosis and others parasitic infections in dogs in the Sudan (Eisa, et al., 1977; Elkhawad, et al., 1979a; Idris, 1985; Saad and Magzoub, 1986; Mohammed and Elmalik, 2000; Mohammed, 2004 and Elmahdi et al., 2006). In South Darfur State, despite Mohammed and Elmalik (2000) who have reported the echinococcosis among dos and foxes, no sufficient information on the epidemiology of the disease in definitive host of the study area. Hence, the present study was conducted to provide further information on the prevalence of gastrointestinal parasites of dogs and to identify the potential risk factors associated with prevalence rate enabling to design feasible and strategic control of gastrointestinal parasites of dogs in areas of similar ecological features. 


\section{Material AND Methods}

\section{Study area:}

The current study was performed at Nyala area, South Darfur State. Nyala, the capital of the State, lies in savanna zone between the latitude $8.30-13.30^{\circ}$ north and longitude $23-15^{\circ}$ east (Fig.1.).

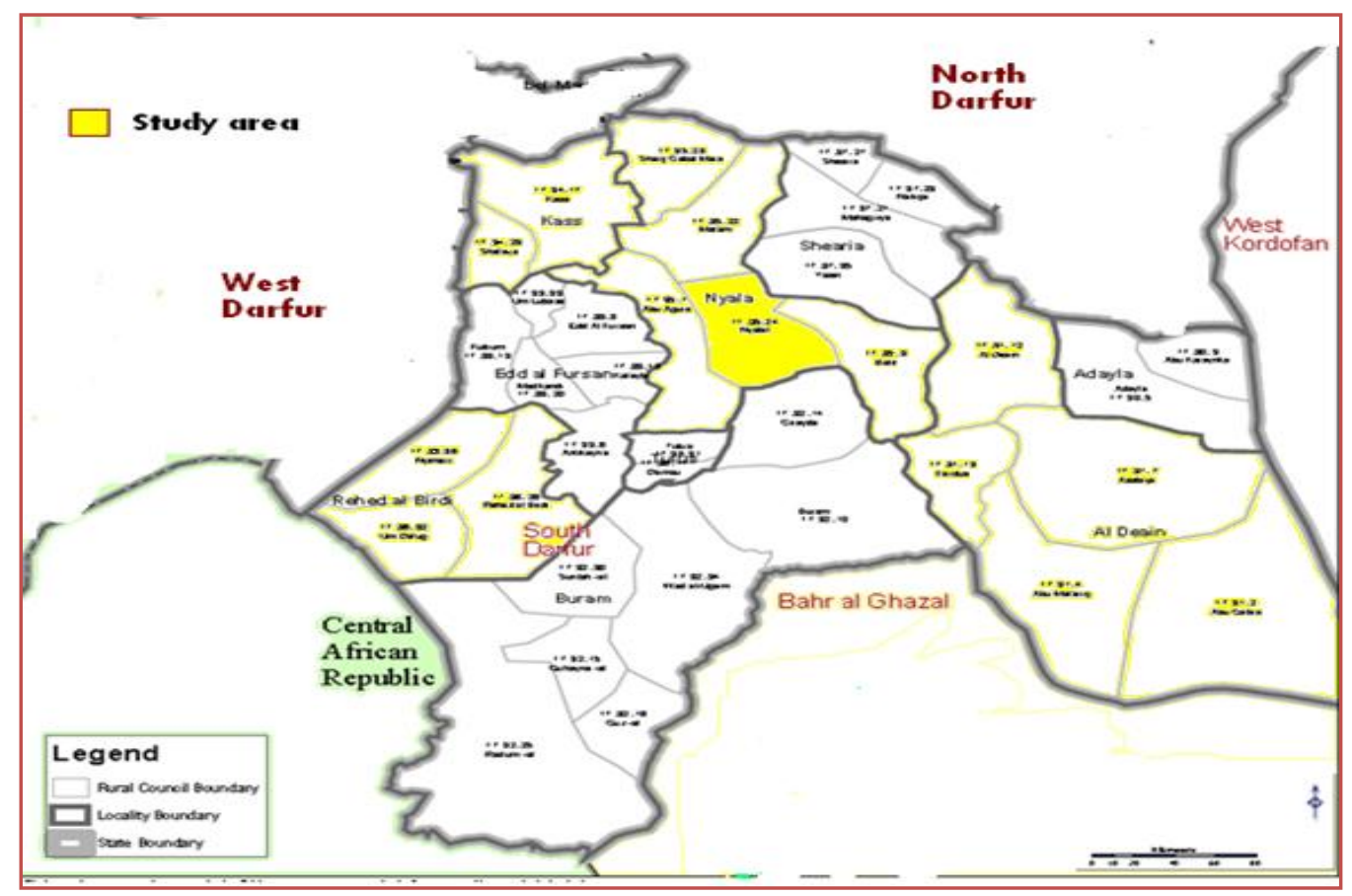

Fig.1.The map of study area.

\section{Ethical Approval:}

An approval for conducting this research has been obtained from Ministry of Animal Resource, Fisheries and Ranching, South Darfur State.

\section{Collection of samples:}

\section{Adult parasite from definitive host (dogs):}

A total of 117 stray dogs in different ages were examined during a rabies control campaign in July 2011 in Nyala for the presence of E. granulosus. The abdominal cavity of each dog was opened carefully. The small intestine was isolated, lighted at both ends and transported in identified plastic bags to laboratory.

\section{Parasitological techniques:}

\section{Post-mortem worm recovery (Sedimentation and counting technique):}

A total of 117 intestines from stray dogs were examined according to WHO/OIE (2001), with some modifications. The intestines of dogs were opened lengthwise, emptied in clean plastic buckets and the mucosal surface scraped with a spatula to ensure that no parasites remain attached. The intestines then were washed in tap water in the same buckets and the contents sieved. The washed intestinal contents and scrapings were placed on a black tray and the worms were counted with the aid of a hand lens, and then preserved in 70\% Ethanol and stored at room temperature for more identification.

\section{Data Analysis:}

Epidemiological data were analyzed by SPSS computer programme (Microsoft version No. 20, USA). Data was analyzed using frequencies, one sample t-test and correlation coefficient.

\section{ReSUlts}

\section{The prevalence of echinococcosis in definitive host (dogs):}

A total of 117 gastrointestinal tracts (GIT) of dogs were examined in Nyala area during the study period. Of these dogs examined, 95.7\% were infected with one to three GIT parasite worms (Fig.2, 3, 
Gastrointestinal Helminthes Infesting Stray Dogs with Emphasis on Echinococcus Spp. in Nyala, South Darfur State, Sudan

4 and 5). The worm burdens identified belonged to four species: Echinococcus granulosus, Dipylidium caninum, Ancylostoma caninum and Taenia spp. (Table 1). The infection rates within location were $87.2 \%$ in south of Nyala and $94.9 \%$ in the north. Whilst, the infection rates within sex of animals were $98.8 \%$ in male and $89.2 \%$ in female.

Table 1. Prevalence of gastrointestinal parasites in stray dogs according to locations in Nyala area

\begin{tabular}{|l|c|c|c|c|}
\hline Species of parasites & \multicolumn{3}{|c|}{ Location } \\
\hline & \multicolumn{3}{|c|}{ South of Nyala (n=78) } & \multicolumn{2}{c|}{ North of Nyala $(\mathrm{n}=39)$} \\
\cline { 2 - 5 } & $\begin{array}{c}\text { No. of positive } \\
\text { animals }\end{array}$ & $\begin{array}{c}\text { Prevalence } \\
\text { rates }(\%)\end{array}$ & $\begin{array}{c}\text { No. of positive } \\
\text { animals }\end{array}$ & $\begin{array}{c}\text { Prevalence rates } \\
(\%)\end{array}$ \\
\cline { 2 - 5 } & & & & $94.9 \%$ \\
\hline Taenia spp. & 68 & $87.2 \%$ & 37 & $61.5 \%$ \\
\hline Ancylostoma caninum & 49 & $62.8 \%$ & 24 & $12.8 \%$ \\
\hline E. granulosus & 3 & $3.8 \%$ & 5 & $2.6 \%$ \\
\hline Dipylidium caninum & 1 & $1.3 \%$ & 1 & \\
\hline
\end{tabular}

\section{Worm counts:}

As shown in table (2), no significant difference was found in total mean worm burdens among sex of animals. Also no significant difference was found in total mean worm burdens among location, although south of Nyala had significantly higher mean worm burdens of Ancylostoma caninum and lowest mean worm burdens of Dipylidium caninum than the north. In addition to that, a significant difference was found in mean worm burdens of Echinococcus granulosus between sexes of animals, where male had higher mean worm burdens of Echinococcus granulosus than female. Also a significant difference was found in mean worm burdens of Echinococcus granulosus between locations, for as much as north of Nyala had higher total mean worm burdens of Echinococcus granulosus than the south.

Table 2. Mean worm burdens ( $\pm S E$ ) of Echinococcus granulosus in stray dogs according to sex and location in Nyala area:

\begin{tabular}{|l|c|c|c|c|}
\hline \multirow{2}{*}{ Species of parasite } & \multicolumn{2}{c|}{ Sex } & \multicolumn{2}{c|}{ Location } \\
\cline { 2 - 5 } & Male & Female & South & North \\
\hline Echinococcus granulosus & $104.0 \pm 99.7^{*}$ & $12.3 \pm 9.1$ & $3.3 \pm 2.3$ & $91.0 \pm 78.3^{*}$ \\
\hline Ancylostoma caninum & $30.0 \pm 6.4$ & $18.2 \pm 5.2$ & $34.5 \pm 7.0^{*}$ & $11.4 \pm 3.7$ \\
\hline Dipylidium caninum & $5.0 \pm 3.0$ & $0.0 \pm 0.0$ & $2.0 \pm 0.0$ & $8.0 \pm 0.0^{* *}$ \\
\hline Taenia spp. & $12.7 \pm 2.1$ & $16.4 \pm 3.7$ & $12.0 \pm 2.1$ & $17.3 \pm 3.5$ \\
\hline Total mean worm burdens & $39.4 \pm 7.2$ & $27.3 \pm 5.4$ & $35.5 \pm 5.1$ & $36.4 \pm 12.2$ \\
\hline
\end{tabular}

$* \mathrm{P} \leq 0.05,{ }^{* *} \mathrm{P} \leq 0.01$

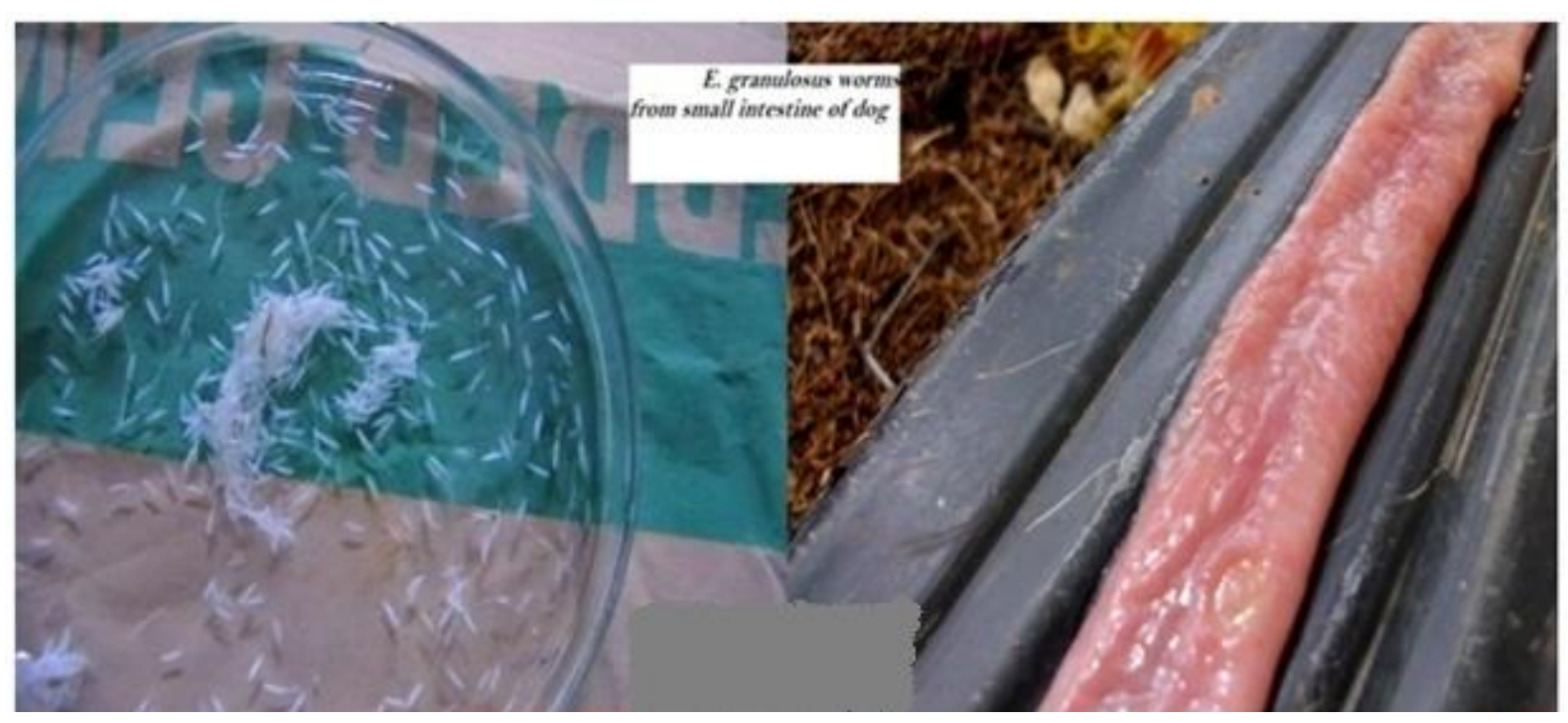

Fig. 2. Echinococcus granulosusworms collected from small intestine of dog. 
El Malaik A. A. et al.

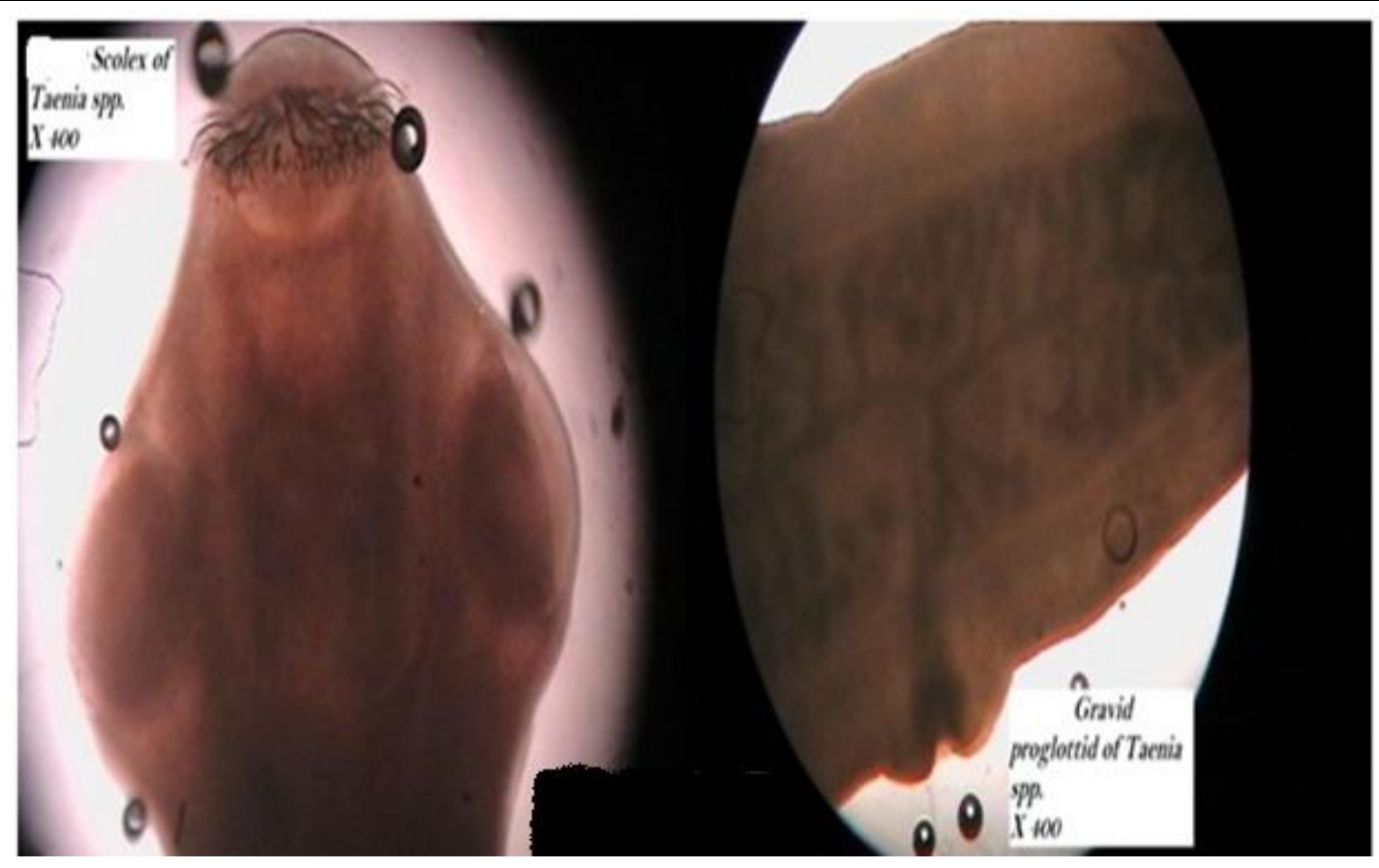

Fig. 3. Scolex and gravid proglottid of Taenia spp.

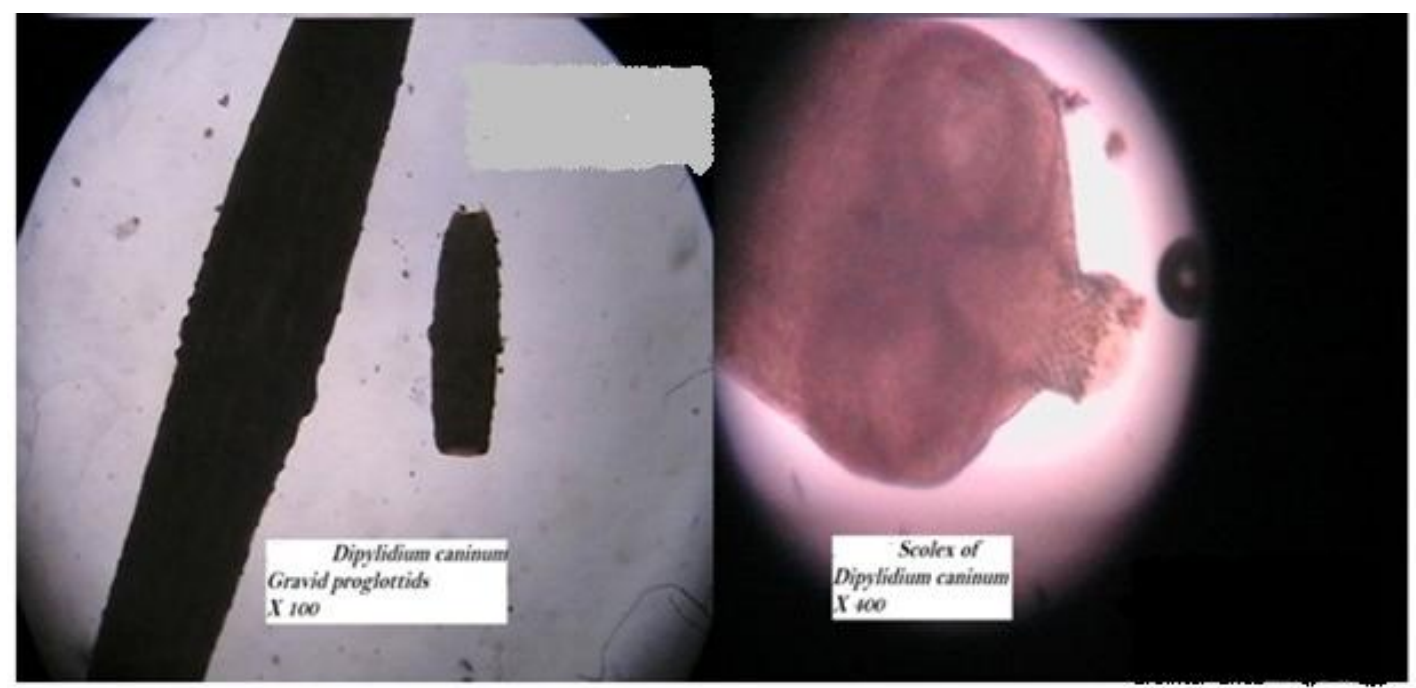

Fig. 4. Scolex and gravid proglottid of Dipylidiumcaninum

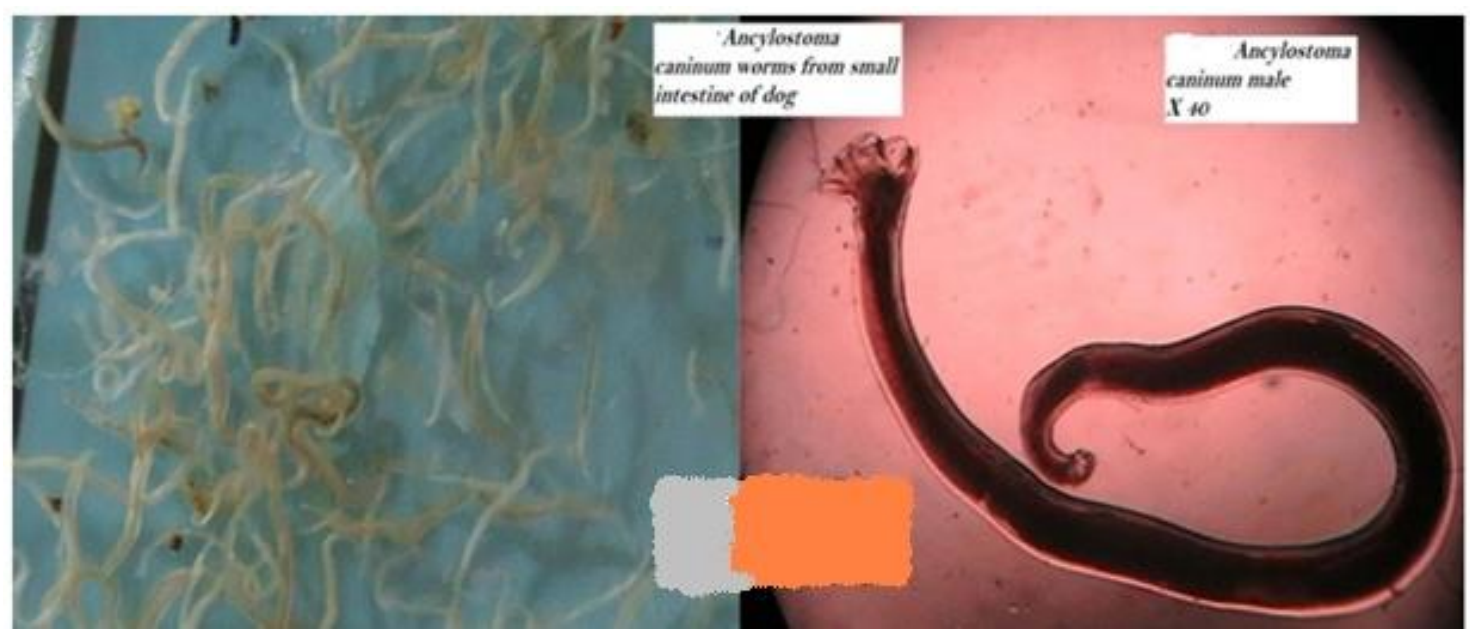

Fig. 5. Ancylostoma caninum worms collected from small intestine of dog. 


\section{DISCUSSION}

Echinococcosis is endemic in sub-Saharan Africa including Ethiopia, Kenya, Mauritania, Sudan, and Tanzania (Romig et al., 2011 and Magambo et al., 2006). Estimate of gastrointestinal burden in stray dogs is useful epidemiological criterion for establishing a baseline of infection at the beginning of a control programme and indicates the potential risk to humans and livestock of being infected with hydatid disease or other zoonotic parasites.

In the current study, of the 117 dogs examined, $95.7 \%$ were founded infected with one to three GIT parasite worms. The high prevalence observed in the present study was in agreement with other studies from Cameroon, South Africa and Ethiopia (Komatangi, 2005; Minnaar et al., 2002, Mukaratirwa and Singh, 2010, Getahun and Addis, 2012 and Zewdu et al., 2010). Previously, ten genera of GIT parasites in dogs were reported in Sudan (Eisa, 1962, 1995 and Eisa et al., 1977) but in the present study, worms recovered from GIT of dogs belonged to four genera, Taenia spp., Ancylostoma caninum, Echinococcus granulosus and Dipylidium caninum. Our results indicated high prevalence rate of Taenia spp, which was in contrast to that found by Eisa (1962) in other parts of Sudan where Taenia hydatigena had a low prevalence (8\%). Similarly, the high prevalence rate of Ancylostoma caninum and low prevalence rate of Dipylidium caninum reported in this study were in contrast to the findings of Eisa (1962) who reported the prevalence rates of $62-78 \%$ for these parasites.

In this study, Echinococcus granulosus had a lower prevalence rate in comparison with that reported previously by Mohammed and Elmalik (2000) in the same area (26.9\%), where They attributed it to the fact that $50 \%$ of the dogs captured in the vicinity of slaughterhouse showed Echinococcus granulosus infection in that study. This finding is in agreement with the work conducted in Khartoum and Omdurman (Eisa et al., 1977 and Elkhawad et al., 1979a), but in contrast to that reported by Idris (1985) in Khartoum Province and Saad and Magzoub (1986) in Tamboul. The low prevalence rate in the present study may be due to change in attitude of the people in the study area, where camel lungs become fit for human consumption in comparison with the previous period (Mohammed and Elmalik, 2000).

The sex of dogs was not significantly associated with prevalence of gastrointestinal parasites in this study despite the high frequency in males compared with females. This finding is in agreement with other works in some parts of the world (Mirzae and Fooladi, 2012; Zewdu et al., 2010; Getahun and Addis, 2012 and Ramirez-Barrios et al., 2004). However, Kirkpatrick (1988) stated that, the higher prevalence of gastrointestinal helminthes in male dogs than female dogs could be attributed to hormonal factors and sex-associated behaviors such as roaming. The high prevalence rate of Ancylostoma caninum encountered in northern Nyala could be attributed to ecological factors, which is characterized by its sandy soil.

A significant difference was found in mean worm burdens of Echinococcus granulosus among locations, for as much as north of Nyala had higher total mean worm burdens of Echinococcus granulosus than the south. These findings may confirm the previous results that indicated to importance of camels in transmission of this parasite in the study area (Mohammed and Elmalik, 2000 and Omer et al., 2010), where most of the camels slaughtering in the abattoirs of northern Nyala. The result of this study is lower than those observed, in the same region previously. So, the low prevalence rate in dogs looks to be true epidemiological relationship to the level of CE observed in slaughtered animals in the study area.

\section{Conclusion}

Examination of 117 GIT of dogs in this study, revealed that dogs are not only important animals in transmission of E. granulosus but also in many zoonotic parasites in the study area.

\section{ACKNOWLEDGEMENTS}

The authors would like to thank the Director of Ministry of Animal Resource, Fisheries and Ranching, South Darfur State for facilities. Special thanks are extended to Mr. A. I. Osman and F. J. Mohammed for technical assistance. The assistance of Mr. M. Khamies and F. J. Addnan for his fruitful assistance during the rabies control campaign is greatly appreciated. 


\section{REFERENCES}

Andersen, F. L. (1997). Introduction to cystic echinococcosis and description of cooperative research project in Morocco. In: Compendium on cystic echinococcosis in Africa and in the Middle Eastern countries with special reference to Morocco (F. L. Andersen, H. Ouhelli, M. Kachani, eds.). Brigham Young University Print Services, Provo, Utah, USA: 1-17.

Dakkak, A. (2003). Le chien et la contamination de l'environnement par les oncospheres d'Echinococcusgranulosus: Cas de 4 régions du Maroc. In: Proc. Soc. Franc, aise Parasitol., Maisons Alfort, France, 16-18 décembre.

Eisa, A. M. (1962). Preliminary survey of parasites of dogs in Upper Nile Province. Sud. J. Vet. Sci. and Anim. Husb., 3(2): 109-117.

Eisa, A. M.; Elkhawad, S. E. and Slepnev, N. K. (1977). A survey of parasites of dogs in Khartoum Province. Proceeding of the $8^{\text {th }}$ Veterinary Conference (Livestock and animal production in the Sudan) 22-26 April: 64-67. openagricola.nal.usda.gov/Record/CAT79720371

Eisa, A. M. (1995). Helminthes in Domestic Animals in the Sudan. First edition, Animal Resource Bank, pp. 254.

Elkhawad, S. E.; Eisa, A. M.; Slepnev, N. K. and Saad, M. B. (1979a). Hydatidosis of domestic animals in the Central Region of the Sudan. Bull. Anim. Hlth. and Prod. Afri., 27: 249251.PMID: 548137.

Elmahdi, I.E, Nakao, M; Sato, M.O. and Ito, A (2006). Echinococcus Canadensis mitochondrial cox1 gene for cytochrome c oxidase subunit 1, partial cds. Accession No.AB271920

Euzeby, J. (1991). The epidemiology of Hydatidosis with special reference to the Mediterranean area. Parassitologia, 33(1): 25-39. PMID:1841192

Garippa, G.; Varcasia, A. and Scala, A. (2004). Cystic echinococcosis in Italy from the 1950s to present. Parassitologia, 46: 387-391.eprints.uniss.it/2675/1/Garippa_G_Articolo_2004_ Cystic.pdf

Getahun, Z. and Addis, M.(2012). Prevalence of Gastrointestinal Helminthes among Dogs in Bahir Dar Town, Ethiopia. World Applied Sciences Journal 19 (5): 595-601.DOI: 10.5829/idosi.wasj.2012.19.05.1935

Idris, Y. A. (1985). Some aspects of epidemiology of echinococcosis/hydatidosis in the Sudan. M.V.Sc. thesis, University of Khartoum. 195pp.

Kirkpatrick, C. E. (1988). Epizootiology of endoparasitic infections in pet dogs and cats presented to a veterinary teaching hospital. Vet. Parasitol., 29: 339-348. Dec;30(2):113-24. PMID:3245104 doi:10.1016/0304-4017(88)90158-6

Komatangi, M. C. (2005). Prevalence of gastrointestinal helminths of dogs in Dschang, Cameroon. J. Cam. Acad. Sc., 5: 11-14. DOI: 10.4314/jcas.v5i1.17684

Magambo, J.; Njoroge, E. and Zeyhle, E. (2006). Epidemiology and control of echinococcosis in subSaharan Africa. Parasitol. Int. 55 (Suppl): S193-S195. doi:10.1016/j.parint.2005.11.029

Minnaar, W. N.; Krecek, R. C. and Fourie, L. J. (2002). Helminths from a peri-urban resource limited community in Free State Province, South Africa. Vet. Parasitol., 107 (4): 343-349. PMID: 12163245

Mirzaei, M. and Fooladi, M. (2012). The prevalence of intestinal helminths in owned dogs in Kerman city, Iran. Sci Parasitol 13(1):51-54.scientia.zooparaz.net/2012_13_01/sp2012-051-054-Mirzaei1.pdf

Mohammed, A. A. (2004). Some Epidemiological Aspects of Echinococcus granulosus and Isolate Characterization in Animals in Darfur Region. Ph. D. Thesis, University of Khartoum, 145 pp.

Mohmmed, A. A. and Elmalik, Kh. H. (2000). The Epidemiology of Cystic Echinococcosis in Nyala Southern Darfur State, Sudan. Sud. J. Vet. Res.: 49-53.sudanjvr.net/doc/vol16/8.pdf

Moro, P. and Schantz, P. M. (2006). Cystic echinococcosis in the Americas. Parasitology International, 55: S181-S186. doi:10.1016/j.parint.2005.11.048

Mukaratirwa, S. and Singh, V. P. (2010). Prevalence of gastrointestinal parasites of stray dogs impounded by the Society for the Prevention of Cruelty to Animals (SPCA), Durban and Coast, South Africa. J. S. Afr. vet. Ass. 81(2): 123-125. PMID:21247022 
Omer, R. A.; Dinkel, A.; Romig, T.; Mackenstedt, U.;Elnahas; A. A.; Aradaib, I. E.; Ahmed, M. E.; Elmalik, K. H. and Adam, A. (2010). A molecular survey of cystic echinococcosis in Sudan. Veterinary Parasitology, 169: 340-346. doi:10.1016/j.vetpar.2010.01.004

Ramírez-Barrios, R. A.; Barboza-Mena, G.; Munoz, J.; Angulo-Cubillan, F.; Hernandez, E.; Gonzalez, F. and Escalona, F. (2004). Prevalence of intestinal parasites in dogs under veterinary care in Maracaibo, Venezuela. Vet. Parasitol. 121 (1-2):11-20. PMID:15110399

Romig, T.; Omer, R. A.; Zeyhle, E.; Hüttner, M.; Dinkel, A.; Siefert, L.; Elmahdi, I. E.; Magambo, J.; Ocaido, M.; Menezes, C. N.; Ahmed, M. E.; Mbae, C.; Grobusch, M. P. and Kern, P. (2011). Echinococcosis in sub-Saharan Africa: Emerging complexity. Veterinary Parasitology, 181: 4347. doi:10.1016/j.vetpar.2011.04.022

Saad, M. B. and Magzoub, M. (1986). Echinococcus granulosus infection in Tampool, Sudan. J. Helminthol., 60: 299-300.PMID: 3794293.

World Health Organization (WHO) (2001). WHO/OIE Manual on echinococcosis in humans and Animals: a Public Health Problem of Global Concern. Eckert, J., Gemmell, M. A., Meslin, F. X., Pawlowski, Z. S., eds. Paris : Office International des Epizooties, 262 pp.

Zewdu, E.; Semahegn, Y. and Mekibib, B. (2010). Prevalence of helminth parasites of dogs and owners awareness about zoonotic parasites in Ambo town, central Ethiopia. Ethiop. Vet. J., 14 (2): 17-30. http://dx.doi.org/10.4314/evj.v14i2.63881 